\title{
Collision-Induced Dissociation of Alkali Metal Cationized and Permethylated Oligosaccharides: Influence of the Collision Energy and of the Collision Gas for the Assignment of Linkage Position*
}

\author{
Jérôme Lemoine and Bernard Fournet \\ Laboratoire de Chimie Biologique, Université des Sciences et Technologies de Lille, Villeneuve d'Ascq, France
}

Dominique Despeyroux and Keith R. Jennings
Department of Chemistry, University of Warwick, Coventry, England

Raoul Rosenberg and Edmond de Hoffmann

Laboratoire de Spectrométrie de Masse, Université Catholique, Louvain La Neuve, Belgium

Tandem mass spectrometry has been used to study the collision-induced decomposition of $\left[\mathrm{M}+\mathrm{Na}^{+}\right.$ions of permethylated oligosaccharides. It is shown that many linkage positions in one compound may be determined by the presence or absence, in a single spectrum, of specific fragment ions that arise from the cleavage of two ring bonds and that the yield of such ions depends strongly on the collision energy and nature of the collision gas. In contrast to the behavior of monolithiated native oligosaccharides, the collision-induccd decomposition of the sodiated and permethylated oligosaccharide samples at low energy leads to preferential cleavage of glycosidic linkages. At high collision energies, the fragment ions formed by cleavage of more than one bond are greatly enhanced, especially when helium is replaced by argon as the collision gas. Furthermore, argon is the more efficient collision gas in inducing fragmentation of the precursor ions. As an example of the application of this method, the discrimination between the $1 \rightarrow 3$ and $1 \rightarrow$-linked mannose residues in the common core of $N$-glycans is described. (J Am Soc Mass Spectromt 1993, 4, 197-203)

\begin{abstract}
A decisive advance was made for the structural elucidation of oligosaccharides with the simultaneous developments of gas chromatography/mass spectrometry (GC/MS) interfacing [1] and Hakomori's methylation procedure [2]. Indeed, the combination of these two techniques enabled the identification of linkage positions by electron ionization mass spectrometry (EIMS) of partially methylated and acetylated alditols [3]. At the same time, the fragmentation schemes for derivatized oligosaccharides were intensively studied by Biemann et al. [4] and by Chizhov and Kochetkov [5, 6]; this

\footnotetext{
* We dedicate this article to the memory of Bernard Fournet.

Address reprint requests to Jérôme Lemoine, Laboratoire de Chimie

Biologique, Université des Sciences et Technologies de Lille, 59655 Villeneuve d'Ascq Cedex, France.
}

work has been extensively reviewed by Lonngren and Svensson [7]. Numerous recent studies have also demonstrated the interest in the use of fast-atom bombardment (FAB) [8] or liquid secondary ionization mass spectrometry (LSIMS) [9] ionization combined or not with tandem mass spectrometry (MS/MS) in the determination of the sequences and branching patterns of native or derivatized oligosaccharides [10-17]. Furthermore, several different types of precursor ions such as $[\mathrm{M}+\mathrm{H}]^{+}[18-24],[\mathrm{M}-\mathrm{H}]^{-}[25],[\mathrm{M}+\mathrm{Li}]^{+}[19$, $26]$, and $[\mathrm{M}+2 \mathrm{Li}-\mathrm{H}]^{+}[27]$, as well as major fragment ions occurring in the FAB source [18, 25], have been used to demonstrate that FAB-collision-induced dissociation (CID) MS/MS may also be used to discriminate between linkage positions in oligosaccharides. Most of the latter results were obtained from 
MS/MS experiments on disaccharides or oligosaccharides containing up to four glucose residues. The proposed mechanism for the production of the ions giving rise to the diagnostic peaks involves the breaking of two ring bonds and requires the opening of the reducing linkage as the first step. Retro-aldol or retro-ene isomerizations then promote the loss of neutral fragments containing two, three, or four carbon atoms from the reducing sugar, depending on the linkage. In infrared laser desorption mass spectrometry, the same mechanism is thought to be responsible for the observed fragmentation of saccharides by the thermal opening of the reducing sugar during the irradiating pulses [28].

If the $[\mathbf{M}+\mathbf{H}]^{+}$ions of oligosaccharides, especially those of higher relative molecular mass $\left(\mathbf{M}_{\mathbf{r}}\right)$, are enhanced by derivatization, the CID of such ions leads mainly to fragmentation at the glycosidic bond without significant cleavage of two ring bonds $[10,13]$; however, information on the lirkage positions may be obtained by CID of peracetylated disaccharides and pentasaccharides [23, 24] or permethylated trisaccharides [18-20], and the well-described specific elimination of the three-linked substituent $\left(\mathrm{OCH}_{3}\right.$ or sugar) on $\mathrm{N}$-acetylglucosamine (GlcNAc) is also of great interest $[11,19,23]$. The spectra obtained by CID of cationized and permethylated oligosaccharides also furnishes useful information from which it is possible to identify with certainty the $2 \rightarrow 3$ and $2 \rightarrow 6$ linked Neu5Ac and, in addition, the $1 \rightarrow 3$ - and $1 \rightarrow$ 4-linked hexose with an $\mathrm{N}$-acetylhexosamine [29]. The differences in the mass spectra given by the $2 \rightarrow 3$ and $2 \rightarrow 6$ sialyl linkages were attributed mainly to the ability of the $2 \rightarrow 6$ branch to chelate the cation, thereby leading preferentially to the production of nonreducing endproduct ions. The work of Laine et al. $[18,20]$ on the differentiation of linkage isomers is also based on likelihood of cleavage of more hindered bonds. Discrimination between the $1 \rightarrow 3$ and $1 \rightarrow 4$ linkages was based on the specific elimination of the substituent linked on the carbon 3 atom, as mentioned previously, together with the fragments arising from the breaking of the two ring bonds.

The aim of the present work was to determine the optimum conditions for the production of these specific fragments. The influence of changing the collision energy from low energies ( $<100 \mathrm{eV}$ ) to high energies (4 keV) was investigated. At high energies, the influence of the nature of the collision gas on the CID of $[\mathrm{M}+\mathrm{Na}]^{+}$ions was investigated. Most reports of the CID of ions derived from oligosaccharides and peptides indicate that helium has been used as the collision gas, but recent studies indicate that significant differences may be observed in the spectra arising from the CID of $(M+H)^{+}$peptides if helium is replaced by a heavier collision gas, such as argon or xenon [30-34]. The heavier collision gas promotes the formation of ions that require multiple bond cleavage for their formation.
Once the optimum conditions were established, the method was used to discriminate between the $1 \rightarrow 3$ and $1 \rightarrow 6$ branches in oligosaccharides having the common core structure of $\mathrm{N}$-glycans.

\section{Experimental}

\section{Materials}

All oligosaccharides used in the present work were purified in the laboratory from biological fluids and characterized by NMR spectroscopy. The Gal $\beta 1$ 6Gal $\beta 1-4 \mathrm{GlcN}$ Ac $\beta 1-2 \mathrm{M}$ an $\alpha$ 1-6Man $\beta$ 1-4GlcNAc (sample 1) and the biantennary Gal $\beta 1-4 \mathrm{GlcNAc} \beta 1-2$ Man $\alpha$ 1-3[GlcNAc $\beta 1-2$ Man $\alpha$ 1-6] Man $\beta$ 1-4GlcNAc (sample 2) were purified from the urine of a patient who had GMI gangliosidosis. The Gal $\beta$ 1-4GlcNAc $\beta 1-$ 2 Man $\alpha 1-6$ Man $\beta$ 1-4GlcNAc (sample 3) and the Gal $\beta 1$ 4 GlcNAc $\beta$ 1-2Man $\alpha 1-3$ Man $\beta 1-4 G l c N A c$ (sample 4) were isolated from the urine of a patient who had Morquio disease. The NeuAc $\alpha 2-6 \mathrm{Gal} \beta 1-4 \mathrm{GlcNAc} \beta 1-$ 3Gal B1-4Glc (sample 5) was purified from human milk.

For each run, $5 \mu \mathrm{g}$ of the permethylated oligosaccharide sample was placed on the probe tip, allowed to dry, and then mixed with $2 \mu \mathrm{L}$ of a 1:1 mixture of thioglycerol/glycerol saturated with NaI.

\section{Tandem Mass Spectrometry}

The low-energy CID experiments were carried out on a Finnigan-M $\Lambda \mathrm{T}$ (San Jose, CA) TSQ 70 instrument. $\Lambda \mathbf{n}$ Ion Tech FAB gun gave a primary beam of xenon at $8 \mathrm{keV}$ and $0.4 \mathrm{~mA}$. The CID of the $\left[\mathrm{M}+\mathrm{Na}^{+}\right.$precursor ion was performed with xenon at 0.8 mtorr (uncorrected gauge reading) in the rf-only collision cell.

High-energy CID spectra were obtained in Warwick and Lille on identical Kratos Concept II HH foursector tandem mass spectrometers of EBEB geometry (Manchester, England). Ions were produced by using an Ion Tech FAB source with 8-keV xenon atoms and then accelerated with a voltage of $8 \mathrm{kV}$. The ${ }^{12} \mathrm{C}$ ion in the isotope cluster of the $[\mathrm{M}+\mathrm{Na}]^{+}$was selected by MS-I and was subjected to CID into the collision cell floating at $4 \mathrm{kV}$ above ground potential. Either helium or argon was used as collision gas, the precursor ion beam being attenuated by $80 \%$ in each case. When switching from one collision gas to the other, care was taken to eliminate cross-contamination of the collision gas by successively evacuating the gas inlet line and flushing it out with the new collision gas. The CID mass spectra were acquired by means of a linked scan of the electric and magnetic field strengths, $E_{2}$ and $B_{2}$. respectively, of MS-II under the control of the DS90 data system. Each mass spectrum is the average of 10 scans. The relatively large amount of sample used in each case, together with the cooling of the probe [35], ensured that the intensity of the precursor ion beam remained constant. 


\section{Results and Discussion}

Abundant oxonium fragment ions are observed in the normal FAB spectrum [10-12] as products of metastable transitions and as products of the CID of $[\mathrm{M}+\mathrm{H}]^{+}$ions of derivatized oligosaccharides. Although such ions are very useful for determining sequencing and branching patterns, no further information on different linkage positions can be obtained except for the $1 \rightarrow 3,1 \rightarrow 4[18-20,23]$, and $1 \rightarrow 6$ [18-20] linking of $N$-acetylhexosamines.

In contrast, very different behavior is observed for $[\mathrm{M}+\mathrm{Na}]^{+}$ions of permethylated oligosaccharides. No significant metastable decompositions of these ions are observed, suggesting the stability of such adduct ions compared with the $[\mathrm{M}+\mathrm{H}]^{+}$counterpart, as mentioned previously by several authors $[17,19,20]$. Thus, although the $[\mathrm{M}+\mathrm{H}]^{+}$ions are absent, the FAB mass spectra obtained with $0.05 \mathrm{M} \mathrm{NaI}$ in the matrix still contain intense peaks attributable to oxonium ion fragments, whereas these peaks are absent when the concentration of $\mathrm{NaI}$ is $1 \mathrm{M}$ or greater. The spectra produced by the CID of $\left[\mathrm{M}+\mathrm{Na}^{+}\right.$ions, however, contain many peaks arising from cationized product ions. We show more particularly that the relative yields of some specific ions originated from multiple bond cleavages are strongly dependent on the collision energy and target gas.

For the designation of these product ions, the nomenclature proposed by Domon and Costello [36] has been adopted. To clarify the fragmentation schemes, only the two bond ring cleavages will be indicated. The $B^{\prime}, C^{\prime}, Y^{\prime}$, and $Z^{\prime}$ fragments correspond to $\mathrm{B}, \mathrm{C}, \mathrm{Y}$, and $\mathrm{Z}$ fragments, with elimination of a methoxyl group.

\section{Influence of Collision Energy}

The mass spectrum given by the CID of the $[\mathrm{M}+\mathrm{Na}]^{+}$ ion of permethylated oligosaccharide 1 at a collision energy of $20 \mathrm{eV}$ in a triple quadrupole mass spectrometer is shown in Figure 1a. The main features of the spectrum are peaks due to $Y(m / z 504,708,953)$ and $C$ $(m / z 259,463,708,912)$ ions that arise from fragmentation of the glycosidic bonds. The only two peaks that arise from ions formed by the cleavage of two ring bonds are those at $m / z 329$ and 533 due to the ${ }^{3,5} \mathrm{~A}_{2}$ and ${ }^{3,5} \mathrm{~A}_{3}$ fragments respectively. These observations are in striking contrast to those reported for the lowenergy CID of cationized native oligosaccharides, the spectra of which contain intense peaks due to product ions that arise from cleavages of the sugar ring [26, 27].

On the other hand, many peaks due to fragmentation of the sugar ring are abserved in the spectrum given by high-energy ( $4 \mathrm{keV}$ ) CID of the same oligasaccharide with argon as the collision gas (Figure $1 b$, Scheme I). The ${ }^{1,5} X_{i}$ series of ions $(m / z 328,532$, $736,981,118.5)$ is particularly useful for the determina-
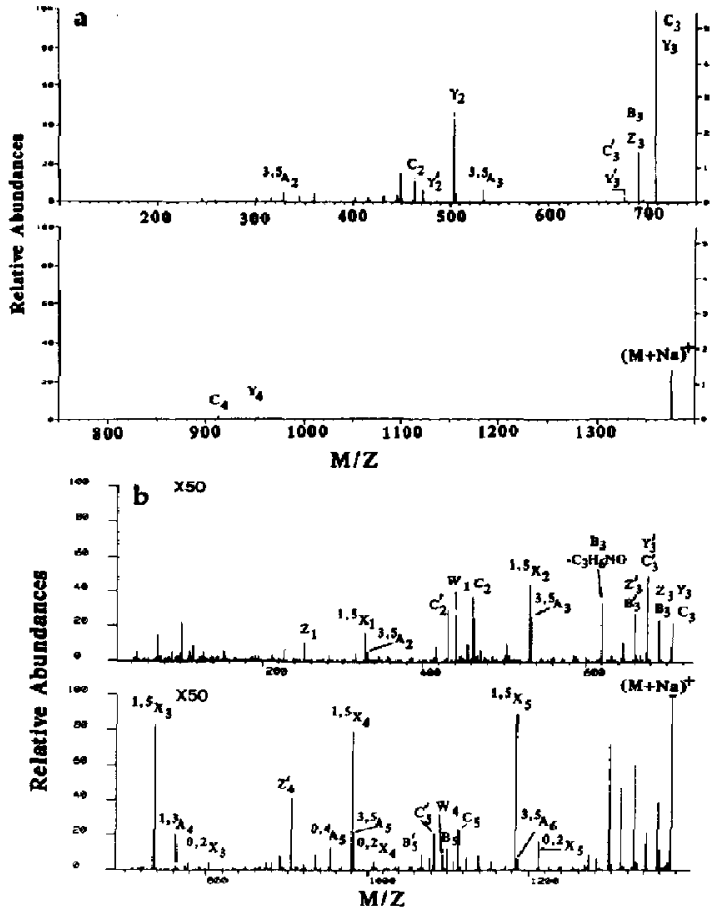

Figure 1. CID spectra of the $(\mathrm{M}+\mathrm{Na})^{+}$ion of permethylated Gal $\beta 1$-6Gal $\beta$ 1-4GlcNAc $\beta 1-2 M a n \alpha 1-6 M a n \beta 1-4 G l c N A c$ (sample 1) obtaincd at low collision energy ( $20 \mathrm{eV}$ ) (a) and high collision energy ( $4 \mathrm{keV}$ ) (b) with argon as the collision gas.

tion of the sequencing and branching patterns, whereas the ${ }^{0,2} \mathrm{X}_{i},{ }^{3,5} \mathrm{~A}_{i},{ }^{0,4} \mathrm{~A}_{i}$, and ${ }^{1,3} \mathrm{~A}_{i}$ product ions are of considerable interest in helping to identify the position of linkage (see later). Moreover, two ions at $m / z \mathbf{4 4 2}$ and 1095 are observed, which indicates a cleavage between the carbon atoms 5 and 6 of a six-substituted sugar, with the elimination of a methoxyl group. Therefore, by analogy with the nomenclature of Domon and Costello [36], and also to avoid any confusion with the $\mathrm{E}$ oxonium type ion described by Chizhov and Kotchekov $[5,6]$ in EIMS of substituted carbohydrates, we propose to designate this cleavage as $W_{i}$.

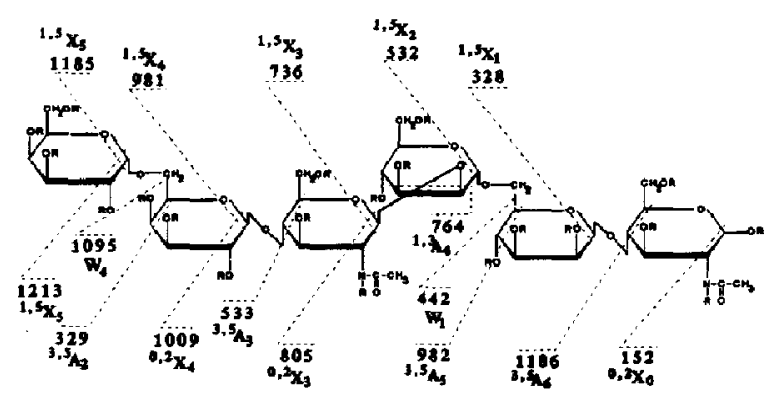

Scheme 1. Fragmentation pattern of permethylated sample 1 obtained by $\mathrm{CID}$ of $(\mathrm{M}+\mathrm{Na})^{+}$ion; $\mathrm{R}=\mathrm{CH}_{3}$. 


\section{Influence of the Nature of the Collision Gas}

Many studies [30, 31, 33, 34] have shown that the use of a collision cell floated at $4 \mathrm{kV}$ above earth potential, resulting in a collision energy of $4 \mathrm{keV}$, is a good compromise in giving a sufficient yield of product ions and efficient collection of low-mass ions without significant loss of transmission between MS-I and MS-II.

Under these conditions, even for precursor ions of $\mathbf{M}_{\mathbf{r}}<1000$, there is a marked change in the relative abundances of fragment ions on switching from helium to argon as collision gas. The most significant changes are a decrease or total lack of $Y$ fragments and a considerable increase in the abundance of ions arising from multiple bond cleavages. For example, in the spectrum given by $\mathrm{CID}$ of the $[\mathrm{M}+\mathrm{Na}]^{+}$of permethylated sample 5 (Figure $2 \mathrm{a}$, Scheme II) with helium as the collision gas, the predominant fragment ion is the $Y_{2}$ fragment ion at $m / z$ 463. When helium is replaced by argon (Figure $2 \mathrm{~b}$ ), the relative abundance of this ion falls considerably. The peaks due to the ${ }^{3,5} \mathrm{~A}_{1}$ fragment at $m / z 486,{ }^{0,4} \mathrm{~A}_{2}$ at $m / z 458$, and $\mathrm{W}_{3}$ at $m / z 850$, present in the spectrum given by argon and specific for a $2 \rightarrow 6$-linked NeuIAc compound, are weak or absent in the spectrum obtained using helium as the collision gas.

Similarly, the abundances of the product ions relative to that of the precursor ion are much greater when helium is replaced by argon as collision gas (compare
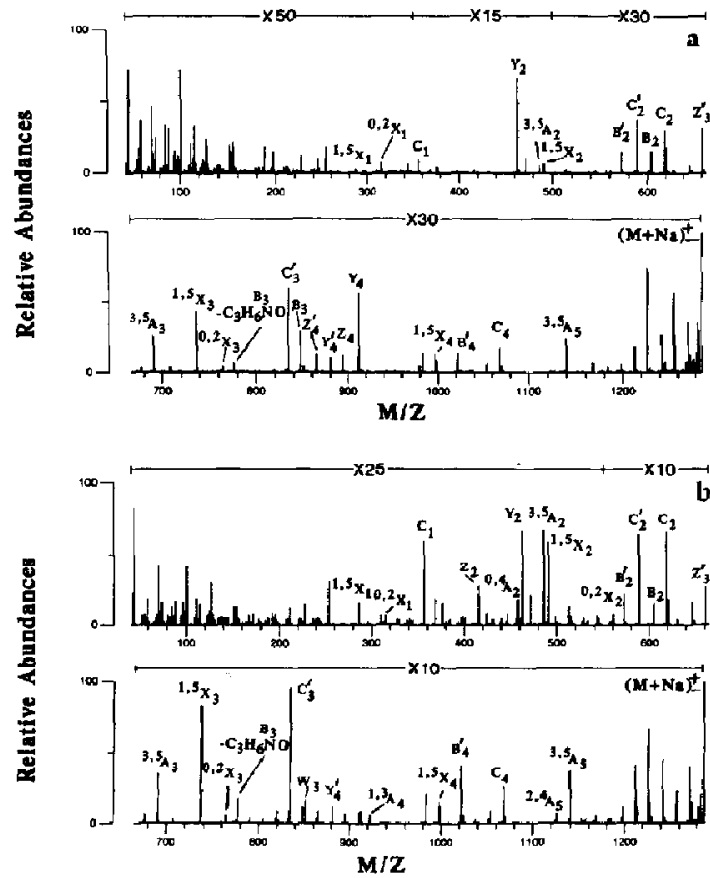

Figure 2. CID spectra of the $(\mathrm{M}+\mathrm{Na})^{+}$ion of permethylated NeuAc $\alpha$ 2-6Gal $\beta$ 1-4GlcNAc $\beta$ 1-3Gal $\beta$ 1-4Glc (sample 5) obtained with $4 \mathrm{keV}$ collision energy using helium (a) and argon (b) as the collision gas.

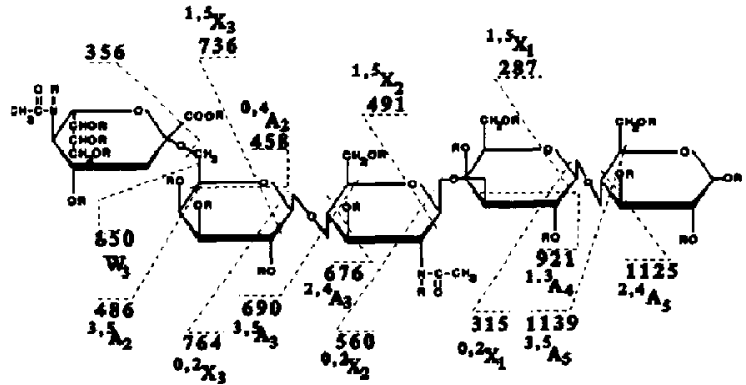

Scheme II. Fragmentation pattern of permethylated sample 5 obtained by $\mathrm{CID}$ of $(\mathrm{M}+\mathrm{Na})^{+}$ion; $\mathrm{R}=\mathrm{CH}_{3}$

the relative multiplication factors). These observations support the conclusions recently reported by BordasNagy et al. [33, 34] for peptides of $\mathbf{M}_{r}>1500$ : The use of argon rather than helium results in more efficient fragmentation of the precursor ion and also leads to an enhancement of fragmentations that require cleavage of more than one bond, indicating the deposition of increased amounts of internal energy.

The strong influence of the collision energy and the nature of the collision gas on the yields of ions that result from the cleavages of two ring bonds indicate the importance of the amount of internal energy deposited in the precursor ion during the collision in leading to the formation of these ions.

First, a comparison at low energy of the fragmentation of natriated permethylated oligosaccharide with the underivatized monolithiated adduct [26] shows that the reaction mechanism consisting of a ring opening followed by either retro-ene or retro-aldol reactions does not occur, as predicted. after methylation. Indeed, in the present work, this reaction is prevented by methylglycosylation of the reducing sugar. A similar effect of methylation was observed by Laine et al. [18, 20]. Consequently, the two observed two ring bond cleavages, the ${ }^{3,5} \mathrm{~A}_{2}$ and ${ }^{3,5} \mathrm{~A}_{3}$ fragments, cannot be accounted for by this mechanism.

Second, the striking difference between the mass spectra produced at low and high collision energies indicates that two distinct fragmentation processes occur: The cleavage of the glycosidic linkages is favored at low collision energy, whereas the cleavage of two ring bonds is predominant at high collision energy, requiring the deposition of higher amounts of internal energy than is available in triple-quadrupole mass spectrometers.

Third, the presence in the spectra of both reducing and nonreducing end-product ions supports the involvement of different fragmentation mechanisms, because the fragmentation pathways described for monolithiated native oligosaccharides lead only to nonreducing product ions [26].

In light of this, if one considers the strong stability of the sodium adduct, it is not inconceivable that A-, $W$-, and $X$-type fragments are formed in a charge- 
remote fragmentation process [37]. In this case, each CID spectrum may represent the sum of a set of charge-remote fragmentation reactions due to potential cationizations at the different glycosidic linkages. This interpretation is supported by the fact that all product ions are cationized, and it is well known that chargeremote fragmentation occurs more readily under highenergy CID conditions.

To explain the observation of peaks arising from both ${ }^{1,5} \mathrm{X}_{i}$ and ${ }^{0,2} \mathrm{X}_{i}$ types of ions, and from both reducing and nonreducing end cleavages in the CID spectra described previously, we propose two decomposition pathways that involve the six-membered ring of the sugar cycle (Scheme III). Decompositions that follow path $A$ should lead to the formation of ${ }^{3,5} \mathrm{~A}$, fragments common to both $1 \rightarrow 4$ and $1 \rightarrow 6$ linkages and ${ }^{1,3} \mathrm{~A}_{i}$ ions common to both $1 \rightarrow 3$ and $1 \rightarrow 2$ linkages. Similarly, decompositions that follow path $B$ should lead to the formation of the ${ }^{0,4} \mathrm{~A}_{i}$ fragment for the $1 \rightarrow 6$ linkage and ${ }^{2,4} \mathrm{~A}_{i}$ fragments for both the $1 \rightarrow 3$ and $1 \rightarrow 4$ linkages. Support for these postulates is presented later.

The previous observations make it clear that highenergy CID coupled with the use of a heavy collision gas, such as argon or xenon, is a promising method for the determination of linkages in sodiated and permethylated oligosaccharides. One interesting point to underline is that the permethylation induces a shift of mass, allowing the ${ }^{0,4} \mathrm{~A}_{i}$ ion to be distinguished from the ${ }^{1,3} A_{i}$ and ${ }^{2,4} A_{i}$ ions, whereas, without derivatization, all of these ions would have the same mass.

Decomposition pathways, as depicted by Scheme III, are also proposed by Poulter and Burlingame [14] to explain the formation of ${ }^{2,4} \mathrm{~A}_{i}$ and ${ }^{1,5} \mathrm{X}_{i}$ ions but carnot account for the observation of ${ }^{2,5} X_{i},{ }^{1,4} X_{i}$, and ${ }^{2,5} \mathrm{~A}_{i}$ product ions in the CID spectra of $[\mathrm{M}-\mathrm{H}]^{-}$ions of oligosaccharides or glycolipids.

\section{Linkage Discrimination}

Many authors have demonstrated the capability of the FAB MS/MS technique to distinguish between some linkage positions, in oligosaccharides [18-29]. The CID at $4-\mathrm{keV}$ collision energy with argon as the collision

Path A

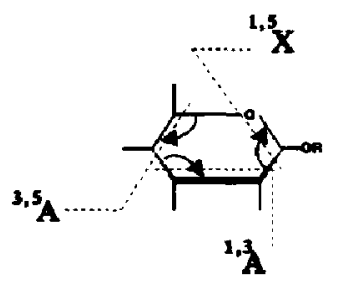

Scheme IIL. Proposed decomposition pathways leading to the observed ions arising from multiple bond cleavages. gas appears to be a powerful method to obtain more information. For example, the isomeric bonds $1 \rightarrow 6$ (Scheme IVa, Figure 3a) and $1 \rightarrow 3$ (Scheme IVb, Figure $3 \mathrm{~b})$ that link the two mannose residues and which correspond to the branching arms of the common core of $N$-glycans, are clearly distinguished. The ${ }^{0,4} \mathrm{~A}_{4}$, ${ }^{3,5} A_{4}$, and $W_{1}$ ions at $m / z 750,778$, and 442 , respectively, characterize the $1 \rightarrow 6$ linkage, whereas the low-abundance fragment ${ }^{1,3} \mathrm{~A}_{4}$ at $m / z 764$ is specific for a $1 \rightarrow 3$ linkage when correlated with the observation of the peak at $m / z 356$ arising from the ${ }^{0,2} X_{1}$ fragment. Furthermore, if the ${ }^{1,3} \mathrm{~A}_{i}$ cleavage is common to both $1 \rightarrow 2$ and $1 \rightarrow 3$ linkages, then the $1 \rightarrow 2$ linkage may be identified by the absence of ${ }^{0,2} \mathrm{X}_{i}$ ion. This ion is observed for all other types of linkages [e.g., with ions at $m / z 152\left({ }^{0,2} X_{0}\right)$ and $m / z 805\left({ }^{0,2} X_{3}\right)$ for a $1 \rightarrow 4$ linkage, an ion at $m / z 356\left({ }^{a, z} X_{1}\right)$ for a $1 \rightarrow 3$ linkage, and at lower abundance with $m / z 356\left({ }^{0,2} X_{1}\right)$ for a $1 \rightarrow 6$ linkage]. The $1 \rightarrow 4$ linkage may also be characterized by the potential presence of peaks due to the ${ }^{3,5} \mathrm{~A}_{i}{ }^{2,4} \mathrm{~A}_{i}$, and ${ }^{0,2} \mathrm{X}_{i}$ fragments in the spectrum.

An example of an application of the capability to distinguish between the two branching bonds is provided by the determination of the structures of the biantennary glycans. This is illustrated by the identification in sample 2 of the antennae that carry the galactose residue in the nonreducing terminal position (Figure 4, Scheme V). The occurrence of $a^{1,3} \mathrm{~A}_{4}$ ion at
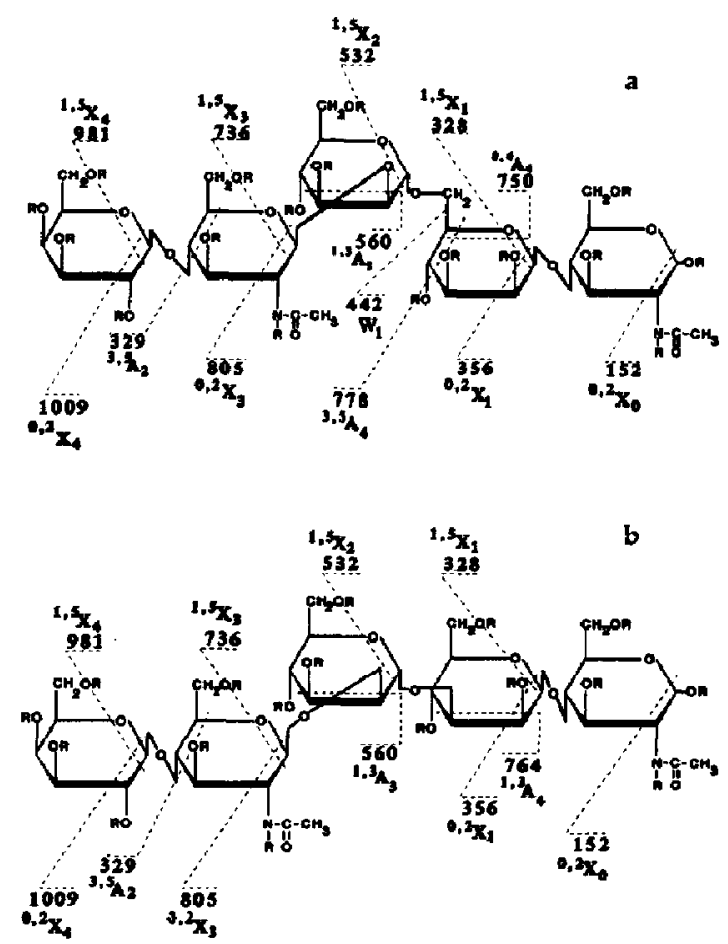

Scheme IV. Fragmentation patterns of permethylated sample 3 (a) and sample 4 (b) obtained by CID of $(\mathrm{M}+\mathrm{Na})^{+}$ion; $\mathrm{R}=\mathrm{CH}_{3}$. 

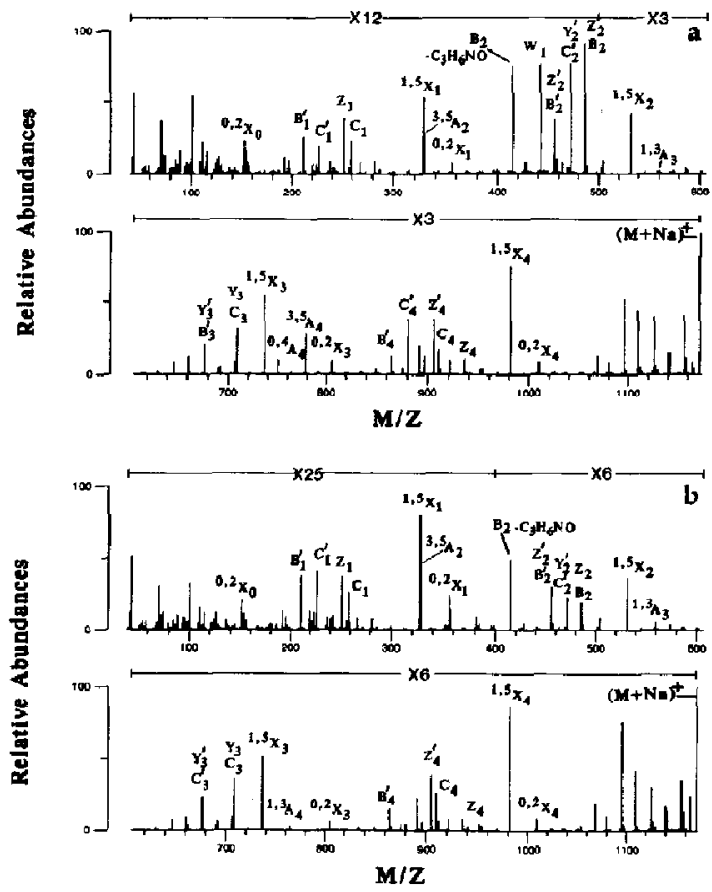

Figure 3. CID spectra of the $(M+N a)^{+}$ion of permethylated Gal $\beta$ 1-4GlcNAc $\beta$ 1-2Man $\alpha$ 1-6Man $\beta 1-4 G l c N A c$ (sample 3) (a) and Gal $\beta 1-4 \mathrm{GlcNAc} \beta 1-2 \mathrm{Man} \alpha 1-3 \mathrm{Man} \beta 1-4 \mathrm{Gl}$ CNAc (sample 4) (b) obtained with $4 \mathrm{keV}$ collision energy with argon as the collision gas.

$m / z 764$ and the ${ }^{3,5} \mathrm{~A}_{4 r}{ }^{0,4} \mathrm{~A}_{4}$, and $W_{1}$ ions at $m / z$ 574, 546 , and 1095, respectively, are consistent with a galactose linked on the $1 \rightarrow 3$ branch.

The spectra given by the CID of $[\mathrm{M}+\mathrm{Na}]^{+}$ions of samples 1 and 5 also contain many diagnostic peaks that allow one to assign different linkage positions. These peaks are summarized in Tables 1 and 2, respectively.

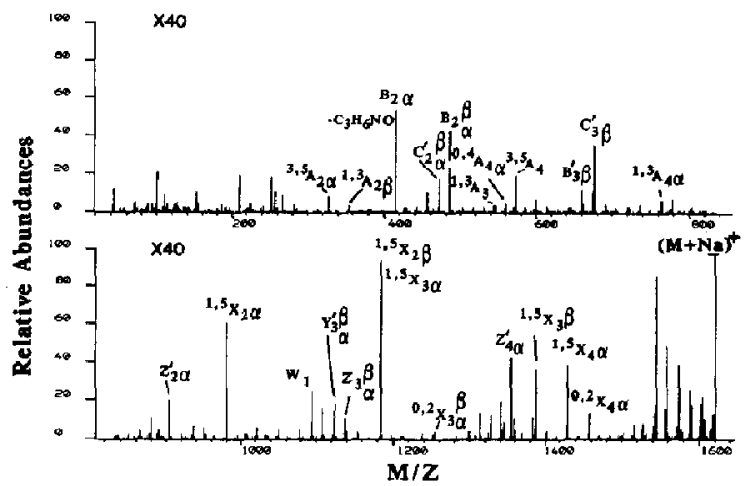

Figure 4. CID spectrum of the $(\mathrm{M}+\mathrm{Na})^{+}$ion of permethylated Gal $\beta$ 1-4GlcNAc $\beta$ 1-2Man $\alpha$ 1-3[GIcNAc $\beta$ 1-2Man $\alpha$ 1-6] Man $\beta$ 14 GlcNAc (sample 2) obtained with $4 \mathrm{keV}$ collision energy with argon as the collision gas.

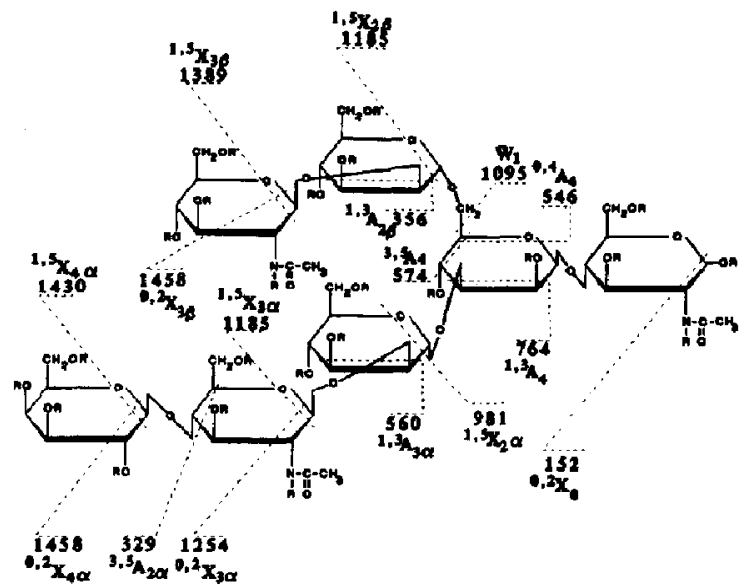

Scheme V. Fragmentation pattern of permethylated sample 2 obtained by $\mathrm{CID}$ of $(\mathrm{M}+\mathrm{Na})^{+}$ion; $\mathrm{R}=\mathrm{CH}_{3}$.

The previous observations clearly indicate that each type of linkage may be identified by the presence or absence, or both, of various diagnostic peaks that may arise from the cleavage of two ring bonds present in the glycosidic cycle. The diagnostic fragments are summarized in Table 3.

\section{Conclusions}

The results presented here demonstrate that the permethylation and cationization of oligosaccharide samples are advantageous not only on the grounds of sensitivity, but also in providing a powerful method of identifying many linkage positions from a single CID spectrum. These identifications are based on the presence or absence, or both, of diagnostic peaks, indicating the formation of ions that arise from the cleavage of two ring bonds within the glycosidic ring. The production of such fragments is probably favored by the strong stability of the cation adduct, and their yield is closely related to the internal energy deposited into the precursor ion during collision. They are essentially absent from CID spectra produced under low-energy conditions $(<100 \mathrm{eV})$. For CID spectra produced under high-energy conditions $(4 \mathrm{keV})$, their production is greatly enhanced if argon rather than helium is used as collision gas; however, because in some cases these

Table 1. Diagnostic peaks given by CID mass spectrometry of the $[\mathrm{M}+\mathrm{Na}]^{+}$ion of permethylated sample 1 (collision energy $4 \mathrm{keV}$, argon as the collision gas)

\begin{tabular}{|c|c|c|c|c|c|c|}
\hline & \multicolumn{6}{|c|}{ Fragment } \\
\hline & ${ }^{0,2} \mathrm{X}_{i}$ & $\mathrm{~W}_{i}$ & ${ }^{0.4} \mathrm{~A}_{i}$ & ${ }^{1,3} \mathrm{~A}_{i}$ & ${ }^{2,4} \mathrm{~A}_{i}$ & ${ }^{3,5} \mathrm{~A}$, \\
\hline $\begin{array}{l}\text { Gal1 } \rightarrow \text { 6Gal } \\
\text { Gal1 } \rightarrow 4 \text { GIcNAC } \\
\text { GlcNAc1 } \rightarrow \text { 2Man }\end{array}$ & $\begin{array}{r}1009 \\
805\end{array}$ & 1095 & & 764 & & $\begin{array}{l}329 \\
533\end{array}$ \\
\hline $\begin{array}{l}\text { Man1 } \rightarrow \text { 6Man } \\
\operatorname{Man} 1 \rightarrow \text { GGIcNAc }\end{array}$ & 152 & 442 & 954 & & 1172 & $\begin{array}{r}982 \\
1186\end{array}$ \\
\hline
\end{tabular}


Table 2. Diagnostic peaks given by CID mass spectrometry of the $[\mathrm{M}+\mathrm{Na}]^{+}$ion of permethylated sample 5 (collision energy $4 \mathrm{keV}$, argon as the collision gas)

\begin{tabular}{lcccccc}
\hline & \multicolumn{5}{c}{ Fragment } \\
\cline { 2 - 4 } & ${ }^{0,2} \mathrm{X}_{i}$ & $\mathrm{~W}_{i}$ & ${ }^{0,4} \mathrm{~A}_{i}$ & ${ }^{1,3} \mathrm{~A}_{i}$ & ${ }^{2,4} \mathrm{~A}_{i}$ & ${ }^{3,5} \mathrm{~A}_{i}$ \\
\hline $\begin{array}{l}\text { NeuAc2 } \rightarrow \text { GGal } \\
\text { Gal1 } \rightarrow \text { 4GlcNAc }\end{array}$ & $\mathbf{7 6 4}$ & $\mathbf{8 5 0}$ & 458 & & & 486 \\
GlcNAc1 $\rightarrow 3 \mathrm{Gal}$ & 315 & & & 921 & 676 & 690 \\
Gal1 $\rightarrow$ 4Glc & & & & & 1125 & 1139
\end{tabular}

Table 3. Potential diagnostic peaks for each position linkage given by CID mass spectrometry of the $[\mathrm{M}+\mathrm{Na}]^{+}$ion of permethylated oligosaccharides

\begin{tabular}{lcccccc}
\hline & \multicolumn{7}{c}{ Fragment } \\
\cline { 2 - 7 } Linkage Pasition & ${ }^{0,2} \mathbf{X}_{i}$ & $\mathrm{~W}_{i}$ & ${ }^{0,4} \mathrm{~A}_{i}$ & ${ }^{1,3} \mathrm{~A}_{i}$ & ${ }^{2,4} \mathrm{~A}_{i}$ & ${ }^{3,5} \mathrm{~A}_{i}$ \\
\hline \hline $1 \rightarrow 2$ & - & - & - & + & - & - \\
$1 \rightarrow 3$ & + & - & - & + & + & - \\
$1 \rightarrow 4$ & + & - & - & - & + & + \\
$1 \rightarrow 6$ & + & + & + & - & - & + \\
\hline
\end{tabular}

+: presence, - : absence

specific fragmentations are near the limit of detection, one might expect that the new methods of dissociation such as surface-induced dissociation or photodissociation will improve their yield.

\section{Acknowledgments}

This investigation was supported by the Centre National de la Recherche Scientifique (Unite mixte de Recherche No. 111, Professeur A. Verbert, Directeur), of the Universite des Sciences et Technologies de Lille. The authors thank Doctor Gérard Strecker for providing the oligosaccharide samples, and Yves Leroy and Guy Ricart for frequent help.

\section{References}

1. Ryhage, R. Anal. Chem. 1964, 36, 759-764.

2. Hakomori, S. I. J. Biochem. 1964, 55, 205-208

3. Hellerqvist, C. G.; Lindberg, B.; Svensson, S.; Holme, T. Lindberg, A. A. Carbohydr. Res. 1968, 8, 43-55.

4. Biemann, K.; DeJongh, D. C.; Schnoes, H. K. J. Am. Chem. Soc. 1963, 85, 1763-1771.

5. Chizhov, O. S.; Kochetkov, N. K. Adv. Carbohydr. Chem. 1966, $21,29$.

6. Chizhov, O. S.; Kotchekov, N. K. Methods Carbotydr. Chem. $1972,6,540$

7. Lonngren, J; Svennson, S. Adv. Carbohydr, Chem. Biochem. 1974, 29, 42 .

8. Barber, M.; Bordoli, R. S.; Sedgwick, R. D.; Tyler, A. N. J. Chem. Soc. Chem. Commun. 1981, 325.
9. Aberth, W.; Straub, K. M., Walls, F. C.; Burlingame, A. L. Anal. Chem. 1982, 54, 2029-2034.

10. Dell, A. Ado. Carbohydr. Chem. Biochem. 1987, 45, 1972.

11. Egge, H.; Peter-Katalinic, J. Mass Spectrom. Rev. 1987, 6, 331-393.

12. Hounsell, E. F.; Madigan, M. J.; Lawson, A. M. Biochem. I. 1984, 219, 947-952.

13. Dell, A. Methods Enzymol. 1990, 193, 647.

14. Poulter, L.; Burlingame, A. L. Methods Enzymol. 1990, 193, 661.

15. Carr, S. A.; Reinhold, V. N.; Green, B. N.; Hass, J. R. Biomed. Environ. Mass Spectrom. 1985, 12, 288-295.

16. Gillece Castro, B.; Burlingame, A. L. Methods Enzymol. 1990, $193,689$.

17. Orlando, R, Bush, C. A.; Fenselau, C. Biomed. Environ, Mass Spectram. 1990, 19, 747-754.

18. Laine, R. A.; Pamidimukkala, K. M.; French, A. D.; Hall, R. W.; Abbas, S. A.; Jain, R. K.; Matta, K. L. J. Am. Chem. Soc. 1988, 110, 6931-6939.

19. Laine, R. A.; Yoon, E.; Mahier, T. J.; Abbas, S.; De Lappe, B.; Jain, R.; Matta, K. Biol. Mass Spectrom. 1991, 20, 505-514.

20. Laine, R. A. Methods Enzymol, 1989, 179; 157.

21. Domon, B.; Müller, D. R.; Richter; W. J.. Org. Mass Spectrom. 1989, 24, 357-359.

22. Müller, D. R.; Domon, Bi; Richter, W. J. Adv. Mass Spectrom. 1989, 11, 1309 .

23. Domon, B.; Müller, D. R. Richter, W. J. Biomed. Environ. Mass Spectrom. 1990, 19, 390-392.

24. Richter, W. J.; Müller, D. R.; Domon, B. Methods Enzymol. 1990, 193, 607 .

25. Garozzo, D.; Giuffrida, M.; Impallomeni, G.; Ballistreri, A.; Montaudo, G. Anal. Chem. 1990, 62, 279-286.

26. Hofmeister, G. E.; Zhou, Z.; Leary, J. A. J. Am. Chem. Soc. 1991, 113, 5964-5970.

27. Zhou, Z.; Ogden, S.; Leary, J. A. J. Org. Chem. 1990, 55, $5444-5446$.

28. Spengler, B.; Dolce, J. W.; Cotter, R. J. Anal. Chem. 1990, 62 $1731-1737$

29. Lemoine, J.; Strecker, G.; Leroy, Y.; Ricart, G.; Foumet, B. Carbohydr. Res. 1991, 221, 209-217.

30. Carr, S. A.; Green, B. N.; Hemling, M. E.; Roberts, G. D.; Anderegg, R. J.; Vickers, R. Proceedings of the 35th ASMS Conference on Mass Spectrometry and Allied Topics, Denver, $\mathrm{CO}$, 1987; p. 830.

31. Martin, S. A.; Johnson, R. S.; Costello, C. E.; Biemann, K. In The Analysis of Peptides and Prateins by Mass Spectrometry; McNeal, C. J., Ed.; Wiley: New York, 1988; p. 135.

32. Martin, S. A. Proceedings of the 37th ASMS Conference on Mass Spectrometry and Allied Topics; Miami, FL, 1989; p. 858.

33. Burdas-Nayy, J.; Despeyroux, D.; Jerunings, K. R. J. Am. Soc. Mass Spectrom. 1992, 3, 502-514.

34. Bordas-Nagy, J-; Despeyroux, D.; Jennings, K. R.; Gaskell, S. J. Org. Mass Spectrom. 1992, 27, 406-415.

35. Falick, A. M.; Walls, E. C.; Laine, R. A. Anal. Biochem. 1986, 159, 132-137.

36. Domon, B.; Costello, C. E. Glycoconjugate 1. 1988, 5, 397-409.

37. Adams, J. Mass Spectrom Rev. 1990, 9, 141-186. 